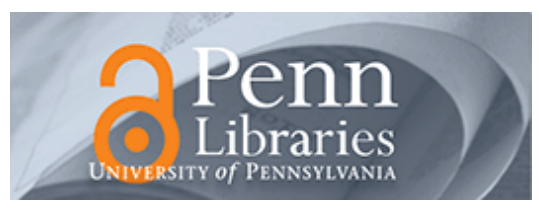

Studies in Visual Communication

Volume 4

Issue 1 Spring 1977

Article 4

1977

\title{
Attribution and Inference in the Interpretation of Candid and Staged Film Events
}

Paul Messaris

Michael Pallenik

Recommended Citation

Messaris, P., \& Pallenik, M. (1977). Attribution and Inference in the Interpretation of Candid and Staged

Film Events. 4 (1), 51-58. Retrieved from https://repository.upenn.edu/svc/vol4/iss1/4

This paper is posted at ScholarlyCommons. https://repository.upenn.edu/svc/vol4/iss1/4

For more information, please contact repository@pobox.upenn.edu. 
Attribution and Inference in the Interpretation of Candid and Staged Film Events 


\section{ATTRIBUTION AND INFERENCE IN THE INTERPRETATION OF CANDID AND STAGED FILM EVENTS}

\section{PAUL MESSARIS MICHAEL PALLENIK}

\begin{abstract}
The two experiments described in this paper deal with the following question: What difference does a viewer's assessment of the degree of control exercised in the production of a film or videotape make in the way a viewer will interpret the events portrayed? By "control" we mean the assessment by the viewer that the filmmaker or TV producer does something deliberately, with the express purpose of implying something to his audience. In our conclusions we shall discuss what difference these ways of interpreting will make to our understanding of how we deal with real and symbolic worlds.
\end{abstract}

There are varying degrees to which control can enter into the process of film or TV production. Most fiction films and TV dramas represent one extreme along this spectrum. Actors, costumes, and settings are chosen deliberately, the action is scripted, camera positions and movements are predetermined, and editing conforms to a plan. In short, control is as complete and all-encompassing as possible, and it is exercised in order to communicate a specific story, moral, or observation.

On the other hand, there are many instances in which the person responsible for the production of a film (or TV program, or videotape) exercises less control over the process. One example might be the researcher recording data of "behavior" for further study. An extreme example might be the television tapes that are produced by surveillance cameras in banks. The security agencies which produce these tapes have almost no influence on the content of the final product. Although they set up the camera in a certain position and they determine when it will be on or off, what ends up being recorded by their camera is not of their making. These videotapes may be taken as examples of minimal control.

Paul Messaris is Assistant Professor of Communication Arts and Sciences at Queens College C.U.N.Y. His research deals with the role of cultural convention as determinants of strategies of interpretation and with the development of methods for studying the role of the mass media as transmitters of culture.

Michael J. Pallenik is a doctoral candidate in Communications at the University of Pennsylvania. His research is centered around the study of the cultural context and consequences of art education in primary schools.
Let us return, now, to the question with which this paper opened: How are viewers' interpretations affected by the degree of "perceived" control that went into the making of a film, videotape, etc.? More precisely, how, if at all, do viewers' interpretations take account of the degree of control which they believe to have been exercised? As a hypothetical case, assume that a viewer is confronted with a number of video tapes made in a bank with the kind of surveillance camera mentioned above. The viewer picks five minutes' of tape to look at, and then we ask him to interpret what he saw. Since he knows the circumstances under which the tapes were made, i.e., since he knows that no director or script-writer has staged what he is looking at, we should expect him to use his knowledge of "real life" in making his interpretations. In other words, this hypothetical viewer might reasonably be expected to draw upon his own experience with banks, together with his beliefs about human behavior, in forming opinions about the type of bank shown in the tape, its probable location, the probable backgrounds and personality characteristics of the various customers, and the like.

Now, assume that we take the same five-minute piece of tape and show it to a different viewer. This time, however, we attach a title and a list of credits at the beginning of the video tape, and we tell this viewer that what he is seeing is the beginning of a telemovie. Under these circumstances, we would expect his interpretations to be made in a different way. If he believes us and treats what he sees as a deliberately staged piece of action, we would expect his interpretations to be aimed at inferring the filmmaker's (or TV producer's) intended meaning. More specifically, it seems to us a reasonable assumption that, under these circumstances, the viewer would treat the elements of the scene before him as purposeful contributions to the beginning of a story line and interpret them accordingly. (In doing so, he might be expected to use his knowledge of the conventions of whatever genre he thinks the movie represents. If, for instance, he thinks that he is watching a crime drama, he might try to sort out the people appearing in the tape into the various kinds of protagonists of a "typical" hold-up scene.)

We shall refer to the first of the two kinds of interpretational strategies outlined above (i.e., what the first hypothetical viewer does) as attribution. The second kind of strategy we shall call inference. Attribution, then, is the use of one's knowledge of real life in making an interpretation. Inference is the effort to make an interpretation conform to one's assumptions about the filmmaker's intention, or, more precisely, to one's assumption that the event in question was intended at all-was other than an accidental or haphazard concatenation of visual events.

The term "attribution" was borrowed from an area of social psychology (attribution theory) which deals with the process by which people interpret behavior they observe in their real-life environment. The correspondence-obviously not exact-between that process and the one for which we are using the term should be apparent. The term "inference" was used to emphasize the fact that, in using this strategy, the viewer goes beyond the events portrayed, to a central, all-encompassing, authorial meaning. This terminology, 
together with the theory which it serves, was developed by Worth and Gross (1974).

To put it briefly, then, this was our hypothesis: The less control a viewer believes to have gone into the making of a film, the more he should use "attribution" to interpret it; the more control, the more he should use "inference." This hypothesis was tested through the two experiments which we shall now describe.

In the first experiment, the situation was very similar to the one described in the hypothetical example above: We took the same piece of film and showed it to two sets of viewers. One group of viewers was told that the film had been made with a hidden camera and that we had picked it out at random from a large amount of similarly made footage. The other group of viewers was told that the piece of film had been clipped out of a longer fiction film which had been written, directed, and acted by a group of film students. In other words, there were two experimental conditions: a minimum-control condition, which we call the candid condition, and a maximum-control condition, which we shall call staged.

The film itself was two minutes long, black-and-white, silent, in $8 \mathrm{~mm}$, and it showed a man sitting in a nondescript room, fidgeting a little, and, at one point, picking his nose. There were no cuts in the film. The film was one uninterrupted length of celluloid. We decided on nosepicking as subject matter because we wanted to present the viewers with a brief, simple event, which would stand out, and which we could reasonably expect most viewers to use in forming judgments of the person in the film.

In the same experiment, we also showed a second film, which was a variation on the first: In that film, there was a second person in the frame, with his back to the camera. This person made talking gestures throughout the length of the film and did not alter his behavior during the nose-picking. Both films were shot at the same time, with two cameras, but in the first one the camera was positioned in such a way as to exclude the talker. We shall refer to the first film as the alone film and to the second as the together film. Each film was shown to two different sets of viewers, corresponding to the two experimental conditions. In all, therefore, four sets of viewers were used. Each group comprised about 15 persons, all of them college students.

After each showing, questionnaires were passed out to the viewers. These questionnaires asked for a variety of things, but for present purposes we shall deal with the following items only. First, each viewer was asked to give five words to describe the person-or persons-in the film. Second, he or she was asked to give an explanation for each word. Finally, each viewer was asked to rate the person(s) in the film on a set of seven bi-polar adjective scales provided by the experimenter. These were seven-point scales, and the viewer had to circle one point of the scale. The adjective pairs were: (1) refined-vulgar, (2) polite-rude, (3) pleasant-unpleasant, (4) calm-agitated, (5) friendly-unfriendly, (6) happy-sad, and (7) intelligent-stupid. Next to each of the scales was a seven-point "confidence scale," ranging from "not at all confident" to "completely confident," on which scale each viewer was to indicate, in a similar fashion, the degree of confidence with which each judgment had been made. Our reasons for soliciting these various response items will become clear in the discussion of the results, below.

Before we present the results, however, let us briefly outline how we expected the experiment to turn out. It should be evident that, broadly speaking, we expected the viewers in the candid conditions to use an interpretive strategy of attribution while those in the staged conditions used a strategy of inference. On a more specific level, we expected the following to happen.

We expected the most obvious interpretation of the nose-picking behavior to be that the nose-picker was rude, vulgar, etc. In the culture of these particular viewers, this is probably the stereotypical interpretation of nose-picking, both in real life and in films. However, we expected the "candid" conditions to result in a variety of other interpretations as well (e.g., "uninhibited behavior," "casual life-style," etc.), since we did not believe that-in the eyes of college students, at least-there would be any necessary connection between real-life nose-picking and the stereotypical interpretation. Thus, we expected the viewers in the "candid" conditions to produce, on the average, relatively moderate judgments of the nose-picker, accompanied by relatively moderate confidence levels.

In contrast to this situation, viewers in the "staged" conditions would be confronted with what they believed was a deliberately staged implication on the part of the filmmaker. Given this belief, we expected them to be much more certain that the most obvious, stereotypical interpretation of the nose-picking was to be accepted. Hence, we expected them to make more extreme "judgments of the nose-picker-in the direction of "vulgarity," "rudeness," etc. - and to be more confident in these judgments.

With these points in mind, we may now examine the results. We shall be dealing exclusively with data on the nose-picker. Judgments of the talker in the "candid" condition were almost identical to those in the "staged" condition. This was as expected: viewers had minimal information on the talker, regardless of condition. Thus, their judgments of the talker were uniformly neutral.

To begin with, then, let us examine the results for scale (1), refined-vulgar, and the associated confidence scale (Table 1). There are two important points here. (a) For both the "alone" and the "together" film, the mean rating of the nose-picker was more extreme (tended toward the vulgar end of the scale) in the staged condition than in the candid one. (b) Similarly, confidence levels were higher in the staged condition for both films. These differences were all statistically significant. Clearly, these results conform to the pattern we had expected.

The data for the other bipolar adjective scales (Table 1) need concern us only very briefly. The results for the polite-rude scale follow the pattern of those for the refined-vulgar scale. Note, also, that on the polite-rude scale, judgments on the "together" film were, in each condition, more extreme and more confident than those on the "alone" film. This was a predictable finding, since nose-picking in public is presumably ruder than nose-picking in private. Except for the pleasant-unpleasant scale, the rest of the bipolar adjective scales produced few significant differences between conditions. This, too, is not a surprising finding: 
TABLE 1

EXPERIMENT 1: MEAN RATINGS AND CONFIDENCE LEVELS

\begin{tabular}{|c|c|c|c|c|}
\hline & \multicolumn{4}{|c|}{ Ratings } \\
\hline & \multicolumn{2}{|c|}{ Alone } & \multicolumn{2}{|c|}{ Together } \\
\hline & Candid & Staged & Candid & Staged \\
\hline refined(1)-vulgar(7) & $4.1 \mathrm{a}$ & $5.5 \mathrm{a}$ & $4.2 \mathrm{~A}$ & $6.0_{A}$ \\
\hline polite(1)-rude(7) & $3.8_{B}$ & $5.5_{B}$ & ${ }^{4.5} \mathrm{C}$ & ${ }^{6.2} \mathrm{C}$ \\
\hline pleasant(1)-unpleasant(7) & 3.5 & 4.2 & $4.1_{b}$ & $4.9_{\mathrm{b}}$ \\
\hline calm(1)-agitated(7) & 4.5 & 5.0 & 4.6 & 4.1 \\
\hline friendly $(1)$-unfriendly (7) & 3.3 & 3.7 & 3.7 & 3.8 \\
\hline happy(1)-sad(7) & 3.6 & 3.8 & 4.5 & 3.8 \\
\hline \multirow[t]{2}{*}{ intelligent(1)-stupid(7) } & 3.4 & 3.3 & 3.6 & 4.0 \\
\hline & \multicolumn{4}{|c|}{ Confidence } \\
\hline refined-vulgar & $3.3_{c}$ & $4.8_{c}$ & $4.7 \mathrm{D}$ & $6.0_{D}$ \\
\hline polite-rude & $3.4 \mathrm{~d}$ & $4.9 \mathrm{~d}$ & 5.0 & 6.0 \\
\hline pleasant-unpleasant & $3.3_{\mathrm{e}}$ & $4.6_{e}$ & 4.9 & 4.8 \\
\hline calm-agitated & 4.8 & 4.9 & 5.3 & 5.0 \\
\hline friendly-unfriendly & $3.2 \mathrm{E}$ & $4.6_{E}$ & 4.3 & 4.1 \\
\hline happy-sad & $3.5_{F}$ & $5.1_{\mathrm{F}}$ & 4.3 & 4.3 \\
\hline intelligent-stupid & 3.7 & 3.8 & 3.7 & 3.4 \\
\hline
\end{tabular}

*Means sharing a common lower-case subscript differ significantly at the .05 level. Means sharing a common upper-case subscript differ significantly at the .01 level.

predictably, nose-picking in this situation was less informative with regard to the other adjective pairs.

Let us now turn to the words chosen by the viewers themselves to describe the nose-picker. We picked out all those words for which the explanation given was the nose-picking. We then assigned these words to two categories: negative judgments ("vulgar," "rude," etc.) and neutral or positive judgments ("uninhibited," "natural," etc.). ${ }^{1}$ Table 2 gives the distribution of these categories by condition for each film. As one can see, these data for the most part conform to our expectations. For the "alone" film, the ratio of unfavorable to other words was $6 / 9$ in the "candid" condition and $8 / 4$ in the "staged" condition. In other words, viewers in the staged condition were more likely to pick the unfavorable, stereotypical interpretation, as expected. For the "together" film, we have, again, a high ratio of unfavorable to other words in the "staged" condition $(21 / 2)$. However, the data for the "candid" condition are puzzling: Only five judgments were based on the nose-picking (all of them unfavorable), making it hard for us to compare this condition with the others. We have no

TABLE 2

EXPERIMENT 1: DESCRIPTIONS OF THE NOSE-PICKER

\begin{tabular}{lcccc}
\hline & \multicolumn{2}{c}{ Alone } & \multicolumn{2}{c}{ Together } \\
& Candid & Staged & Candid & Staged \\
\hline Negative descriptions & 6 & 8 & 5 & 21 \\
Neutral/positive descriptions & 9 & 4 & 0 & 2 \\
\hline
\end{tabular}

explanation for the low number of words based on nose-picking in this condition.

Overall, then, the results of the first experiment conformed to our expectations. For both the "alone" and the "together" film, the "staged" condition produced more negative and more confident judgments of the nose-picker than the "candid" condition. We had expected that this would occur if viewers in the "candid" conditions tended toward using attribution and viewers in the "staged" conditions tended toward using inference. Therefore, the results of this experiment are consistent with the conclusion that such was indeed the case. In other words, the results are consistent with our initial hypothesis: The less control a viewer assumes to have gone into the making of a film, the more he will tend to use real-life knowledge to interpret it; the more control he assumes, the more he should base interpretations on what he assumes the filmmaker to have intended, and therefore implied by the very way he organized his film.

For the second experiment, we prepared a videotape in which an individual posing as a subject waiting for an experiment picked his nose either while waiting by himself or in the presence of another individual. The second experiment was modelled after the first one, but it was not a straightforward replication. It differed from the first in three important ways. First, all subjects, regardless of condition, observed the nose-picker both alone and in the presence of another person. Second, the experiment used videotape in such a way as to try to convince the subjects in the "candid" conditions that they were watching a "live" event, occurring at the very moment of observation. Finally, by employing an open-ended questionnaire and an interview in addition to rating scales, we tried to get detailed information-lacking in the first experiment-on the reasons subjects gave for their judgments of the nose-picker.

As with the first experiment, two tapes were made. Both tapes contained sound. Although neither tape contained any edits, each tape can be divided into four sections. The first and fourth sections, each approximately five minutes in length, contained a shot of an empty waiting room. Only viewers in the candid conditions saw these two sections. The second section of the tape begins with a "secretary" showing the nose-picker into the room and asking him to wait until "they" are ready. The nose-picker sits down to wait, briefly looks around the room, begins shuffling through some magazines on a table in front of him, and finally selects two to leaf through. This section, lasting approximately a minute and a half, is termed the "alone" section. The third section, the "together" section, begins with the same secretary showing a second person into the room and asking him to wait. (In the tape condition, this person was supposed to be a "fellow-subject," waiting for the fictional "experimenters" to show up. In the real life condition, this person was the administrator of the experiment we are describing.) After trading "hellos," the second person (referred to, from now on, as the experimenter) sits down to wait, and the nose-picker returns to his magazine. After shuffling through some magazines, the experimenter initiates a casual conversation with the nose-picker. The conversation lasts until the secretary reenters about five minutes later and asks both to follow her out of the room. The two tapes differ 
with regard to the point at which the nose-picker picks his nose. In the tape shown in the alone conditions, the nose-picker picks his nose while waiting by himself. In the tape used in the together conditions, nose-picking occurs about half-way through the conversation, while the experimenter is talking.

Forty paid volunteers served as viewers, 10 in each of the four conditions. All were university students and participated in the experiment either alone (20) or in pairs (20). Viewers were told one of two cover stories.

In the candid conditions, viewers were led into an observation room containing a television monitor that was already screening the first section of the tape, a shot of an empty room. The monitor was hooked up to a VTR (videotape recorder) situated in an adjacent office, but the viewers were led to believe that they were witnessing a live monitor. The experimenter announced that several researchers (unidentified) had become interested in the effects on character and personality judgments of viewing people via television; that another subject, whom he did not know, had been scheduled for the same time but would be shown into the waiting room appearing on the monitor; that there was a closed-circuit television system hooked up between that room and the observation room; and that the camera was hidden and the room rigged for sound. The experimenter then told candid-condition viewers that when the unsuspecting person (the nose-picker) was shown into the waiting room, he (the experimenter) would leave and be "shown" into the room, where he would pretend to be a fellow-subject, waiting for the experiment. After about five minutes, he would return to the observation room, where both he and the observing subjects would fill out a questionnaire on their impressions of the waiting individual. A short interview to help the research group structure a more formal experiment would follow the questionnaire.

In the staged conditions, the VTR was in the same room as the monitor. It was turned off when the subjects entered but preset for the beginning of the second section (alone) of the tape. The experimenter wore different clothes from those used in the taping. The experimenter told viewers that he was finishing a television lab in which he had written and directed a film and that, as part of the course requirements, he had cut the film into segments of different sizes and was screening them to groups of students, the purpose being to discover how judgments would change depending on the segment viewed. Viewers would watch one of the segments and then fill out a questionnaire and participate in an interview.

As with the first experiment, then, there were four conditions in this second experiment: (1) alone-candid, (2) alone-staged, (3) together-candid, (4) together-staged. Viewers in each condition made judgments about the nose-picker on 13 bipolar adjective scales similar to those used in the first experiment. Likewise, a seven-point confidence scale was appended to each rating scale. Of the 13 rating scales, six were considered critical to this experiment: refined-vulgar, polite-rude, pleasant-unpleasant, calm-agitated, friendlyunfriendly, warm-cold. The remaining scales were fillers. As expected, there were no significant differences between any conditions in judgments made on the filler rating scales. Our discussion will focus on the critical scales and the statements viewers made about them. How did we expect subjects in each of the four conditions to judge the nose-picker on the six critical scales?

We expected that judgments by alone-candid viewers would be determined by two factors. As with the first experiment, we expected the private, "candid" nose-picking to be relatively uninformative, on the average. In fact, during the interviews, only four of the 10 alone-candid viewers gave nose-picking as a reason for making any judgment about the nose-picker. Furthermore, since the nose-picker was dressed attractively and engaged in a pleasant conversation with the experimenter, alone-candid viewers would see him as "acting naturally" and as a "nice guy." They would make positive, although not necessarily very confident, judgments about him.

In the together-candid condition, on the other hand, the contradiction presented by a conservatively dressed student pleasantly engaged in a conversation while picking his nose would preclude the lumping together of positive judgments across several scales under a broad personality description ("nice guy"). Together-candid viewers would have to pay closer attention to each particular rating scale and to the subtleties of the nose-picker's behavior. Judgments and confidence levels on each critical scale would vary depending on the type and number of reasons which viewers could observe in assessing the nose-picker's traits.

The judgments of viewers in staged conditions would, we believed, be determined by their assumption of the filmmaker's control over the film. Most of us tend to believe that a filmmaker is responsible for what happens within his film; the determination of his intentions and the meaning of his film depend upon this accountability. For the alone-staged viewers then, the nose-picking would be assumed to be intentional and, therefore, relatively more communicatively meaningful than for the alone-candid viewers. In contrast to the alone-candid viewers, seven of the 10 alone-staged viewers gave nose-picking as a reason for making judgments about the nose-picker as a character (distinguished, of course, from the real-life person who was, rather than was portraying, a nose-picker). Since alone-staged viewers would be assessing the nose-picking as a symbolic event, they would treat it with confidence as implying something negative about the nose-picker.

Similarly, we expected that together-staged viewers would make negative judgments about the nose-picker. Unlike viewers in the together-candid condition, who would try to estimate the nose-picker's position on each scale, togetherstaged viewers would treat the nose-picking as a clear implication by the filmmaker that the nose-picker was not a nice person. Consequently, judgments by together-staged viewers would be very confident.

In Table 3 we have lumped the six critical scales together to give a general overview of the distribution of viewers' judgments in each condition. The scales may be treated as running from extreme positive judgments (1) to extreme negative judgments (7).

Table 3 indicates that the pattern of judgments by viewers in each condition generally-but not entirely-confirmed our expectations. The majority of judgments by alone-candid viewers were positive. A large number of judgments by alone-staged viewers were negative, but not extreme. 
Together-candid viewers made fewer extreme, positive judgments and more negative ones than alone-candid viewers. In the together-staged condition, judgments tended to be very extreme; however, the distribution of judgments is bimodal. We shall return to this bimodality a little later.

TABLE 3

EXPERIMENT 2: DISTRIBUTION OF JUDGMENTS*

\begin{tabular}{lrrrr}
\hline & \multicolumn{2}{c}{ Alone } & \multicolumn{2}{c}{ Together } \\
& Candid & Staged & Candid & Staged \\
\hline $1(+)$ & 14 & 8 & 5 & 8 \\
2 & 16 & 7 & 21 & 16 \\
3 & 16 & 10 & 10 & 4 \\
4 & 8 & 11 & 10 & 4 \\
5 & 5 & 15 & 5 & 8 \\
6 & - & 7 & 5 & 15 \\
$7(-)$ & 1 & 2 & 4 & 5 \\
Mean $=$ & 2.6 & 3.8 & 3.3 & 3.7 \\
\hline
\end{tabular}

* "Positive" judgments $(+)$ are represented by lower numbers ( 1 to 3 ); "negative" judgments (-) by higher numbers (5 to 7 ).

Table 4 gives the mean rating levels for each of the six critical scales by condition and supports the distribution data shown in Table 3. Judgments by alone-candid viewers are extremely positive. Alone-staged viewers are negative or neutral in their judgments. The exception is the polite-rude scale (mean=2.1) where alone-staged viewers found specific reasons (e.g., "He didn't pick his nose while you were with him"; "He kept the conversation going when he didn't have to") for making judgments on this scale. Together-candid viewers are less positive than alone-candid viewers, but are clearly negative only on the refined-vulgar scale (mean=4.7). Judgments by together-staged viewers, while somewhat negative, tend to hover about the mid-point of each scale. Given Table 3, however, this can be seen as resulting from the bimodal distribution of judgments. Significance tests reveal a general candid-staged main effect across the critical scales, with the exception of the polite-rude scale and the refined-vulgar scale.

Table 4 also shows the mean confidence levels for each rating scale by condition. The most surprising finding is that subjects in all four conditions were able to make highly confident judgments. In no case were confidence levels in the lower half of the seven-point continuum. Among the four conditions, the high confidence of alone-candid viewers is the most puzzling. Here, it is interesting to note that in the alone-candid condition mean confidence levels on critical scales averaged 1.5 points higher than mean confidence levels on filler scales. (A similar pattern was found for the other conditions.) The high confidence displayed by alone-candid viewers on critical scales can, perhaps, be best understood by taking two factors into consideration. First, it may be that judgments on the critical scales could be based-partially, at least-on the nature of the situation (i.e., a waiting room in which a certain typical range of behavior may confidently be
TABLE 4:

EXPERIMENT 2: MEAN RATINGS AND CONFIDENCE LEVELS*

\begin{tabular}{|c|c|c|c|c|}
\hline & \multicolumn{4}{|c|}{ Ratings } \\
\hline & \multicolumn{2}{|c|}{ Alone } & \multicolumn{2}{|c|}{ Together } \\
\hline & Candid & Staged & Candid & Staged \\
\hline refined (1)-vulgar(7) & 3.8 & 4.5 & 4.7 & 4.1 \\
\hline polite(1)-rude(7) & 1.9 & 2.1 & 2.9 & 3.6 \\
\hline pleasant(1)-unpleasant(7) & $2.0_{a}$ & $3.4 a$ & 2.9 & 3.4 \\
\hline $\operatorname{calm}(1)$-agitated $(7)$ & $2.8_{b}$ & $4.8 \mathrm{~b}$ & 3.6 & 4.5 \\
\hline friendly (1)-unfriendly (7) & $1.8_{\mathrm{A}}$ & $3.4_{A}$ & 2.8 & 3.4 \\
\hline \multirow[t]{2}{*}{$\operatorname{warm}(1)-\operatorname{cold}(7)$} & $3.5_{c}$ & $4.5_{c}$ & 3.5 & 4.3 \\
\hline & \multicolumn{4}{|c|}{ Confidence } \\
\hline refined-vulgar & 4.9 & 5.4 & 5.9 & 5.2 \\
\hline polite-rude & 5.8 & 6.2 & 6.2 & 6.2 \\
\hline pleasant-unpleasant & 5.8 & 5.9 & 6.2 & 6.3 \\
\hline calm-agitated & 5.0 & 5.6 & 5.8 & 5.3 \\
\hline friendly-unfriendly & 5.6 & 5.3 & 6.2 & 6.6 \\
\hline warm-cold & 4.2 & 5.2 & 5.5 & 5.6 \\
\hline
\end{tabular}

* Means sharing a common lower-case subscript differ significantly at the .05 level. Means sharing a common upper-case subscript differ significantly at the .01 level.

expected) rather than on the actual behavior of the participants in the situation. Second, alone-candid viewers made statements to the effect that the nose-picker was acting "naturally," etc. Given these factors, gross behavioral events (e.g., keeping the conversation going) may have been sufficiently reliable indicators of general traits to allow for confident judgments. When the high confidence of alone-candid viewers is taken into consideration, it is not surprising to find a general lack of numerically significant findings in Table 4. The table must be interpreted in terms of general trends.

With this in mind, Table 4 tends to confirm our expectations. Judgments by alone-staged viewers tend to be somewhat more confident than judgments by alone-candid viewers; and judgments by together-staged viewers tend to be somewhat more confident than judgments by alone-staged viewers. The various confidence scales for together-candid viewers, however, are difficult to interpret, for we had expected that confidence in this condition would vary with extremity of judgment. Extreme negative or positive judgments would be very confident due to careful attention to the nose-picker's behavior, while lower confidence levels would be associated with neutral responses. Table 4 indicates that together-candid viewers showed relatively little variation in confidence levels.

In general, the together-candid condition produced results which we cannot entirely account for. We have pointed out that in this experiment's together-candid condition, nose-picking conflicted with the positive attributes of the nose-picker's dress and conversation. As we had expected, this discrepancy elicited from the viewers closer attention to the more subtle details of the nose-picker's behavior (e.g., 
"His voice tended to drop off at the end of his sentences"; "His answers came too quickly after your questions"). Contrary, however, to our expectations-or, at least, to our design-some of the together-candid viewers resolved this discrepancy by doubting the "candidness" of the nose-picking (although not necessarily the truthfulness of the experimenter; the possibility was brought up that he too was being duped by the higher authorities for whom the study was being performed). Of the eight viewers who reported that they had observed the nose-picking, six said that they believed that it might have been staged rather than candid. Each of these six had previously participated in at least one psychology experiment; four had been in three or more. Moreover, five of these six viewers reported that, in spite of their doubts about the candid nature of the event they were witnessing, they attempted to treat it as though it were real. They pretended that the waiting-room situation was candid, even though their prior experience suggested that it wasn't. Our interviews with together-candid viewers, however, indicated that the effects of doubt and pretending upon judgments were not uniform. For some viewers, a rating scale was treated as an implication on the part of the experimenters and interpreted in a way similar to that used by together-staged viewers. Other viewers saw or pretended to see the same scale in terms of the nose-picker's "natural" personality. And, finally, some viewers saw the implications of the experimenters as "masking" the nose-picker's true character and either sought out more confirming or disconfirming information in his behavior or simply rated the nose-picker opposite to the inferred implication. Thus, the together-candid condition failed to provide us with the information for which it had been intended, i.e., how viewers who believed in the candidness of the taped situation would interpret it. However, the results of this condition were not without interest within the context of our overall scheme, as we hope to show in the course of the following discussion of the together-staged condition.

We have already noted (Tables 3 and 4) that the distribution of judgments by together-staged subjects was bimodal. What could account for this? As part of the interview, we obtained from all viewers information on whether they had observed the nose-picking, whether they had thought it noteworthy, and how they had used it in making judgments. In the staged-together condition, six viewers reported having observed the nose-picking and used it in explaining their judgments; one viewer reported having observed it but not having considered it noteworthy; and three viewers reported that they were not sure the nose-picker had picked his nose. It is this 6-4 split between users and nonusers of the nose-picking as judgmental evidence which appears to account for the bimodality observed in the distributions in the staged-together condition.

In pursuing this interpretation, we computed the mean rating levels for the six using and four nonusing viewers on each critical scale. These numbers confirm the explanation given above for the biomodality. On each scale, viewers who did use the nose-picking made negative judgments about the nose-picker, while those who did not made positive judgments.

The consequence of using vs. not using the nose-picking in making a judgment of the nose-picker was probably predictable. What is of interest in this condition is that so many viewers (four out of 10) did not attend to the nose-picking. We interpret this result to be illustrative of the difference which "staging" makes to a perceiver's attention to and interpretation of a scene.

As Birdwhistell (1970:151) has pointed out, one of the ways in which fictional conversations (not only in movies but also in literature, the theater, and comic books) depart from reality is in the regularity and orderliness of turn-taking: with relatively rare exceptions, conventional fictional speakers exchange lines without interruption and the focus of the encounter shifts back and forth from one speaker to another in concert with this exchange. This is perhaps most nicely illustrated when a fictional conversation is filmed in a two-shot and the camera's focus literally shifts back and forth between two speakers in a single frame. All this is quite contrary to many real-life conversational situations, in which speakers' lines overlap or interrupt each other and, even in the absence of verbal synchrony, the meaning of an encounter is nevertheless located not in a single participant (the "speaker") but in an interaction in which all participants are continuously engaged. Given this state of affairs, it is also reasonable to assume that an observer of a fictional ("staged") conversation applies different rules to this observation from those which he would apply to the observation of a real-life conversation. Specifically, we want to suggest that, when in the presence of a staged conversation, the typical viewer has learned to shift his attention from one character to another in conjunction with the exchange of spoken lines; whereas, when confronted with a real-life conversation, the observer cannot as easily disregard the (non-verbal) contribution of a non-speaker to the ongoing event. In terms of this experiment, then, we might say that the viewers in the together-candid condition had to pay attention to both "speaker" and "listener," whereas those in the together-staged condition could selectively focus their attention on the "speaker" alone. Since the nose-picking occurred when the nose-picker was acting as listener, this interpretation would account for the relatively high number of viewers who "missed" the nose-picking in the together-staged condition. It should also be noted, however, that together-candid viewers had an additional reason for paying attention to the nose-picker even when he was not speaking; they had been asked to assess his personality. (Finally, we should also repeat that, in the first experiment, the "talker" was filmed with his back to the camera, thus directing attention to the "nose-picker" at all times and vitiating the comparability of the two experiments in this respect. The reader should also recall that the film used in the first experiment was silent.) 
If this interpretation of our results in the together-staged condition is accepted, then it would appear that the second experiment, too, confirms our expectations about the differences between what Worth \& Gross have called "attributional" and "inferential" interpretational strategies (with due regard, of course, for the problematic results in the second experiment's together-candid condition).

To recapitulate, then: Those aspects of a film or videotape which a viewer assumes to be free of control (or authorial purpose) will be interpreted according to interpretational rules appropriate to the corresponding real-life event (i.e., he will use the interpretational strategy of attribution). On the other hand, those symbolic events which he assumes to have been staged will be interpreted according to what he assesses as the producer's intent (i.e., he will use inference).

Several observations need to be added to the above explication of our experiments. In the experiments we have just described, we were concerned mainly with the polarization and confidence of interpretations. This should not be taken to mean that we believe such extreme interpretations and the confidence with which they were made to be the most important, most frequent, or most typical aspects in which interpretations vary according to perceived degree of control. Our argument in this respect was specific to the films we used and the kinds of viewers who saw them. A different kind of film might have elicited other kinds of differences. All we wanted to show was that, at least in some cases, perceived degree of control does make a difference to the final outcome of the interpretation and that this difference stems from the use of different interpretational strategies (attribution vs. inference).

The "significant event" in our experimental films-a character's action (i.e., the nose-picking)-represents only one of the many ways in which meaning can be built into a film. We have said nothing in this paper about editing, camera angles, choice of lenses, etc., although it is on these aspects of film, treated as signs of what to attend to, that most film theorists have concentrated. However, some recent film research has gone in the direction of dealing with the characters' actions, motions, positioning, etc. Some investigators have become exasperated with the long and generally unproductive search for linguistic-like units of the order of editing (and other such essentially "framing" devices) and are now turning their attention toward the actual events within the temporal or spatial "frame." For example, Bettetini (1973:55) suggests that it may be time to begin borrowing from kinesics and proxemics for the analysis of film. The results of our experiments would suggest the following: Possible similarities between fiction-film events and real-life events on the articulatory level are not to be taken as evidence for a similarity on the level of meaning. In other words, the uncritical application of the findings-as distinct from the methods-of kinesics, proxemics, etc., to fiction film may lead to error. There is another side to the above observation. Some investigators of the communicational aspects of body motion have traditionally used obviously staged films (and posed photographs) with their informants. The implicit assumption behind this kind of work seems to be that the informants' interpretation of the staged material is identical to what it would be if they were confronted with the corresponding real-life event. This, of course, is the assumption whose fallacy we have tried to show in this study. By using staged material in their research, investigators are ending up with detailed information on the meaning of acted facial expressions, gestures, etc., but questionable evidence on the communicational patterning of body motion in real life. ${ }^{2}$ Naturally, there are nuances with which the attribution-inference distinction-as presented here-does not deal. We would be the first to acknowledge that these nuances are lost in our data, in part because of the quantitative form of the bulk of these data. For example, it may well be that a given viewer's beliefs about some aspects of real-life behavior are actually the product of familiarity with supposedly realistic fictional portrayals of that kind of behavior (on TV or in movies). To the extent that this is true, the viewer's use of attribution as an interpretive strategy may unconsciously involve reliance on fictional codes, conventions or stereotypes of behavior.

Conversely, since fiction films rarely deliberately proclaim their artificiality-indeed, they usually purport to be realistic representations-we cannot assume that a viewer will always maintain an awareness of the "stagedness" of that which he is watching. In the experiments we desoribed, the brevity (and the pedestrian quality) of the films we used made it difficult for the viewer to forget the explicit introductory information as to the nature ("candid" vs. "staged") of the films. But with a feature-length fiction film, in which exciting or moving things may happen, whatever detachment a viewer may have started out with can frequently give way to an illusion of reality or to a so-called suspension of disbelief. Under such circumstances, it is reasonable to assume that "attributions" may coexist with "inferences" in a particular viewer's interpretations of a specific film.

In general then, what seems to have been clarified by these experiments is our understanding that viewers of filmed events do not use the same strategies when interpreting symbolic events which they have assumed to be real that they use to interpret events which they assume to be acted or contrived. Further we have shown that it is the amount of control that the viewers assume to have been exerted in the production of the event which determines in large part the strategy used in its interpretation. This is not only of importance in helping us to understand how we deal with our fictional and real worlds when seen on film in a context of "narrative," "news," or "documentary," but also is important in helping us clarify how we may interpret "scientific" footage of human behavior in field, classroom, and experimental conditions. The assumptions we make about the behavior of the producer of a symbolic event play at least as great a part as the assumptions we make about the behavior of the "actors" in "real" or "symbolic" worlds. It might even be said that these assumptions help us to 
determine which events we want to label "real" or "symbolic."

\section{NOTES}

${ }^{1}$ Here is a list of the words in question, classified into our two categories, by condition. "Alone" film, "candid" condition $(\mathrm{N}=15)$; negative words: gross, common, vain, gross, gross/unmannerly; neutral/positive words: uninhibited, humanistic, human, real, natural, typical, normal, anyone. "Alone" film; "staged" condition $(\mathrm{N}=14)$; negative words: obnoxious, bore, slob, boisterous, inconsiderate, gross, strange, no manners; neutral/positive words: uninhibited, unashamed, open, normal. "Together" film; "candid" condition ( $N=15)$; negative words: gross, rude, insecure, bad manners, sick. "Together" film; "staged" condition ( $N=19)$; negative words: rude, ill-mannered, crude, common, gross, repulsive, antagonistic, rude, gross, rude, ignorant, slob, repulsive, careless, slob, no manner, rude, impolite, vulgar, rude, rude annoying; neutral/positve words: normal, frank.

${ }^{2}$ This is one of the points made by Birdwhistell (1970:153-155) and Mead (1975) in discussions of this type of research.

\section{REFERENCES CITED}

Bettetini, Gianfranco

1973 The Language and Technique of the Film. The Hague: Mouton.

Birdwhistell, Ray L.

1970 Kinesics and Context. Philadelphia: University of Pennsylvania Press.

Mead, Margaret

1975 Review of: Darwin and Facial Expression (Paul Ekman, ed.). Journal of Communication 25:1.

Worth, Sol, and Larry Gross

1974 Symbolic Strategies. Journal of Communication 24:4. 